\title{
Youth Development Program in Northern Manitoba
}

\author{
Christopher D. Brown \\ Brandon University
}

\author{
Brandee Albert \\ Thomson Community Circle Coordinator
}

This article describes a study of the Cultural, Economic, Political, and Social Youth Leadership Development Program (CEPS), an identity-building program for disengaged youth, conducted by a community-university alliance in northern Manitoba, Canada. The study was conducted through the lens of transformative learning theory. Findings indicate participation in CEPS strengthened the physical, spiritual, emotional, and mental well-being of the participants. CEPS provided life skills that inspired and motivated youth to make positive choices to enhance the quality of their lives, and provided knowledge and leadership skill development. The CEPS program also developed the participants' agency to make a difference in their lives, their families, and their communities.

\section{Key Words: Aboriginal, youth, leadership, transformative, success}

In 2011, a Community-University Research Alliance project known as the Vital Outcome Indicators for Community Engagement (VOICE), received a five-year grant from the Social Sciences and Humanities Research Council of Canada. This research project brought community partners, organizations, and university researchers together for the purpose of helping children and youth from First Nations, Métis, and Inuit communities in northern Manitoba to achieve greater educational and career success. Brandon University and the University College of the North, two small universities located in rural Manitoba, were co-applicants in this Community-University Research Alliance project.

The VOICE project has received provincial and national interest because of the unique partnerships and the intention for all of the projects to be community initiated and governed. Unique to this research is that community circles create Success Pathways and drive the research process by identifying, reviewing, and suggesting research plans. University personnel provide support and guidance, as well as conduct research. This project is about making communities and researchers true partners in the co-creation and dissemination of knowledge. One of the communities involved in this research alliance is Thompson, Manitoba.

The Thompson Community Circle identified the Cultural, Economic, Political, and Social Youth Leadership Development Program (CEPS), a youth development program, coordinated and managed by Manitoba Keewatinowi Okimakanak, as a Success Pathway because of its importance to youth in and around Thompson. CEPS is an innovative program intended to enhance the cultural, economic, political, and social strengths of emerging Aboriginal adults (aged 15-29) in northern Manitoba, Canada.
Developed through the support of the Manitoba Assembly of Chiefs (n.d.), CEPS Youth Leadership Development Program fosters the following: "revitalization and re-connection to culture; education on the history of First Nations people; united approaches to self-determination; skills development and knowledge enhancement in cultural, social, political, and economic areas; and youth empowerment" (Assembly of Manitoba Chiefs, Para. 2).

\section{Context}

Thompson, located in northern Manitoba $740 \mathrm{~km}$ from the provincial capital of Winnipeg, is referred to as "the hub of the North" because it is a connector for the surrounding smaller communities. Thompson is the largest urban center for hundreds of kilometers and has a population in excess of 10,000. Many people within the city of Thompson have a disposable income in excess of most other Canadian cities, which is largely due to their employment in nickel processing at Vale Mine. Vale Mine employs approximately $20 \%$ of the city's employable citizens (The Canadian Business Journal, 2014). Thompson also has a high population of underemployed citizens. Currently, over half of the citizens in Thompson are of Aboriginal ancestry. While the city is becoming more diverse with the recent influx of immigrants and the loss of part of the mining operation, the city continues to be divided along economic and Aboriginal/non-Aboriginal lines (Personal communication, Thompson Community Circle, 2012).

\section{CEPS Youth Leadership Development Program}


The CEPS program aims to enhance individual growth in cultural, economic, political, and social areas. These four areas were identified by the Aboriginal youth as necessary for Aboriginal youth leadership development. CEPS is a program based on what youth need and desire in order to develop into strong leaders. CEPS incorporates a vast amount of teachings that help youth reconnect with their culture and traditions. Youth learn about the economics of the world that surrounds them and they come to understand the politics of their communities. CEPS encompasses the mind, body, and spirit, and connects youth with their family, community, and nation. The program respects the diversity of First Nations and establishes that Aboriginal communities all face common challenges. CEPS provides support to youth so that young leaders can be positive change agents.

Each component of this program incorporates the balance of the four realms of the medicine wheel including physical, spiritual, mental, and emotional aspects. The medicine wheel is an ancient and powerful symbol of the Universe used by Indigenous people of North and South America. It carries many important teachings about the interconnectedness and inter-relatedness we have as individuals, amongst each other and amongst life on earth. The medicine wheel is an excellent foundation to use with CEPS, as it encourages youth to self-reflect on their own potential and to make positive changes in their lives.

The cultural connection provides opportunities for youth to reflect on their own personal identity as Indigenous people. Together, youth have come to learn more of their own culture, heritage, and history and to appreciate the traditional teachings and Elder involvement. This approach instills pride within the youth participants. Youth are more engaged when they learn about whom they are (Erikson, 1968; Phinney \& Chavira, 1992).

First Nation and Metis history provides youth with an understanding of the struggles encountered because of colonization. Youth become more aware of the oppressive and assimilative practices that have existed for centuries in Canada and the impacts of these practices on them as young people today. More importantly, youth explore ways to suppress the negative effects of colonization at a personal and social level, by being taught to embrace the positive that they have control over in their lives. Class discussions provide a positive atmosphere for young people to learn and work in unity to encourage perseverance within their communities.

CEPS provides youth an opportunity to gain the life skills they need to move on in their journey. Youth learn the basic life skills that would support them in achieving employment and/or education.
CEPS also provides knowledge and teachings that youth can apply in their personal lives, education, and employment. Youth begin to understand how their own economic standing impacts their life, community, and country. They also begin to learn to make sound fiscal choices through an economic lens.

The CEPS program is intended to create youth empowerment. Youth have the opportunity to selfreflect, which strengthens their identity. Youth become aware of their physical, mental, spiritual, and emotional well-being, which enhances their selfconcept. Youth build their self-esteem and cultural identity, which also has positive implications for their self-determination. Youth become empowered to create positive changes in their lives. Youth empowerment is evident among past CEPS participants who have gone on to finish their high school diplomas and continued to post-secondary education. Past participants have also moved to big cities to pursue their dreams and have become immersed in their culture and gained meaningful employment.

Youth leadership is encouraged in CEPS. Developing a sense of ownership is important, and this is made possible by ensuring participant input, providing authentic feedback, and having responsibilities in the program delivery. This is incorporated into the program through the election of a youth chief, who acts as a representative for the participants. It allows youth to recognize the importance of voting and community engagement.

Elder involvement and traditional teachers are critical components of the CEPS Youth Leadership Development Program. Elders provide guidance for the transmission of oral history as well as guidance about traditions while promoting respect and unity among the group. The Elders have led ceremonies as part of CEPS, including sharing circles, sweat lodges, and opening and pipe ceremonies. Traditional knowledge keepers have also come to share their teachings, stories, and knowledge with the group, so that youth have a good understanding about the value and importance of their Indigenous and Metis cultures.

It is important for CEPS to strengthen existing partnerships and create new partnerships with the valuable resources available within the communities. The participation of existing youth resources, Aboriginal organizations, social service agencies, non-profit groups, and community volunteers is essential in ensuring that youth receive a wealth of information from individuals and groups with extensive knowledge and experience. CEPS demonstrates how a community can build partnerships, collaborate, and work collectively to ensure its success. The ultimate goal of CEPS is to 
provide youth with a positive and respectful learning environment in which the participants will learn from each other while building on new ideas and enhancing individual and collective capacity to address specific issues. CEPS has many assets that support struggling young people to enter and complete the program. The participants are provided with free tuition, training allowance, all learning materials, and transportation to project sites. Upon completion, the participants receive a certificate. In addition, the Manitoba Keewatinowi Okimakanak Youth Program assists participants who complete the CEPS program to secure employment, education, or other personal goals. These supports and incentives help keep youth motivated and engaged in CEPS.

\section{Theoretical Framework}

The theoretical framework that guides this research is transformative learning theory. Transformative learning occurs when individuals participate in activities that involve learning about a different perspective (worldview) and then integrate that different perspective into their current perspective, thereby expanding it. Fundamentally, a transformative learning experience is akin to a paradigm shift, but at an individual level. Transformative learning theory establishes that, as a function of taking on a new perspective, people go through a process that transforms their identity (Mezirow, 2000).

From a pedagogical perspective, two primary conditions must be met for transformative learning to occur: an environment that provides the learner with the potential to develop a disorienting dilemma and an opportunity to critique and reflect within the setting (Taylor, 2009). Both of these conditions are integral to the CEPS program, the aim of which is to encourage personal growth (Assembly of Manitoba Chiefs, n.d.).

Taylor (2009) identified five factors that promote transformative learning: the learner's life experiences, opportunities for dialogue and critical reflection, a holistic orientation, an awareness of context, and authentic relationships. Because of their significance to the present study, each of these five factors will be discussed below.

\section{Life Experiences}

The participants' and facilitators' life experiences have an impact on the constructivist interactions in CEPS. The participants' prior experiences may contribute to the breadth and depth of their interactions with their learning and participation in class dialogue. According to Taylor (2009), the more varied life experience a person has, the greater the potential for and magnitude of transformative learning. Taylor (2009) suggests that it is important for facilitators to understand how prior experiences may create more or less resistance to change in some learners.

\section{Dialogue and Critical Reflection}

Dialogue is a critical element of transformative learning theory (Mezirow, 1991). Based on the constructivist framework that supports transformative learning, it is believed that people experience transformation through dialogue. Dialogue may be either internal (through our inner voices) or external (through dialogue with others). According to Taylor (2009), such dialogue is vital for critical reflection to occur. Thus, "dialogue becomes the medium for critical reflection to be put into action, where experience is reflected on, assumptions and beliefs are questioned, and habits of mind are ultimately transformed" (Taylor, 2009, p. 9). Mezirow (2000) posits that effective dialogue includes the following ideal conditions: access to more reliable and thorough information; an absence of a sense of coercion; a space and place to openly discuss alternative perspectives; "an awareness of the context of ideas and, more critically, reflective of assumptions, including their own" (pp. 13-14); an equitable opportunity to discuss perspectives, a strong desire to understand; and a continual desire to question, continue to learn and challenge common sense.

\section{Holistic Environment}

A holistic environment is predicated upon creating a safe place in which to share and to work through emotional crises. If participants do not feel safe to reflect on and express their beliefs, they will not be able to challenge their own beliefs, values, and assumptions. Expecting that learning may be an emotional enterprise, emotions are an important consideration in CEPS and emotional experiences are expected to provide much of the impetus for change (Kumashiro, 2009). Group dynamics may also facilitate change by affecting the participants' capacity for dialogue and reflection (Taylor, 2009).

\section{Context of the Learning Experience}

The context of the learning experience also needs to be appreciated and is a critical and integral aspect of CEPS. Taylor (2009) states that it is important to take into consideration "the surroundings of the immediate learning event, the personal and professional situation of the learners' present time 
(their prior experience), and the background context that is shaping society" (p. 11). According to Taylor (2009), some life experiences, such as living in poverty or seeing friends being disadvantaged because of the racialization of their identities, may contribute to the likelihood that an individual will experience transformative learning when they learn how oppression operates.

\section{Authentic Relationships}

Authentic relationships are an important prerequisite for transformative learning (Cranton, 2006; Cranton \& Carusetta, 2004a, 2004b; Taylor, 2009). Having authentic relationships, where facilitators are able to develop meaningful, genuine relationships with participants also flows well within the CEPS program. It is through building trusting relationships that participants may feel comfortable sharing and taking risks in class. Facilitators, who teach humbly, recognize their own lifelong journey of learning, as well as that of their participants.

Additionally, they press forward through participant discomfort for the sake of creating a space for substantive personal change, providing the basis for relationships that can affect significant growth in participants. Clarification of the facilitators' intentions and working through issues around authority encompass Aboriginal values and ensure that participants have voice (Tisdell, 1998; Welch, 2006). This element is common to much pedagogy: participants will learn better when they have an authentic relationship with their facilitator. This "best practice" also translates to greater opportunities for transformative learning, because participants feel comfortable and trusting (Cranton \& Carusetta, 2004a, 2004b).

According to Taylor (2009), transformative learning can occur when participants become challenged to examine values and perspectives through which they make sense of the world and their thinking becomes substantially changed by the experience. Transformative learning includes learners identifying "problematic ideas, beliefs, values, and feelings; critically assessing their underlying assumptions; testing their justification through rational discourse; and striving for decisions through consensus building" (Taylor, 2009, p. 3). Transformative learning theory also recognizes the need for "crises" in learning in order to bring about considerable personal change. Not only are feelings critical to personal transformations, but also "feelings must be intentionally evoked and engaged when the educational purpose is to foster transformative learning" (Yorks \& Kasl, 2006, p. 46).
Transformative learning refers to being fundamentally changed by critically reflecting upon significant problems that one encounters in life (Mälkki, 2010). According to Mezirow (2009), by taking on a new perspective, people go through a process that changes their identity. Determining whether there was a perspective change is the key to understanding the impact of CEPS on participants' lives because transformative learning changes the way one understands the world. This is different from other forms of learning because it is not "a change in what we know; transformation is a change in the way we know" (Kilgore \& Bloom, 2002, p. 124). The transformative potential for the participants in CEPS is explored in this study.

Transformative learning theory was chosen to support this work because of its connection to emerging adult learners involved in learning of this type (Tisdell, 2007). Although transformative learning theory is not formally part of CEPS, the critical reflection upon assumptions embedded in the program content had the potential to create cognitive tension and emotional discomfort, leading to transformative learning by creating disorienting dilemmas for the participants (Mezirow, 2012). Hence, transformative learning theory provides a way to understand the process of cognitive growth during learning processes such as those provided via CEPS (Taylor, 1994; Tisdell, 2007).

\section{Methodology}

This study used qualitative research methods to explore participants' perceptions of the eight-week CEPS Youth Leadership Development Program that took place in the spring of 2012. It ran from Monday to Friday (30 hours/week). Letters were handed out on the first day of the program inviting participation in the study. Seven out of the twentythree participants in the CEPS program, and the two facilitators agreed to be interviewed. The facilitators were participants in a previous iteration of the CEPS program. All participants have been given pseudonyms. The participants in CEPS were young male and female adults between the ages of 19-29. All were of mixed or Aboriginal heritage and had been selected for participation in CEPS based on their goodness of fit according to their level of financial and social distress.

After the program concluded, 60-minute personal interviews were conducted to learn about participant and facilitator experiences. The intent of the interviews was to inquire how the participants, who often had been marginalized and felt disenfranchised from previous educational ventures, experienced this program. We (the researchers) inquired about what 
they valued within the program. We also examined how the participants saw themselves growing as a result of what they had learned within the program, and if and how the program had changed them.

The interviews were transcribed and coded thematically using NVivo software. The thematic analysis was conducted using Merriam's (2009) inductive and deductive comparative method first through the lens of the facilitators and then through the lens of the participants. These themes are presented in the voice of participants in order to provide a rich, thick, description that honors the participants' willingness to speak about their participation and growth as a result of the program.

\section{Findings}

The research findings are broken down into two parts. The first part examines the program through the lens of the facilitators' experiences when they were participants in the program, as well as most recently, when they were facilitators. The emergent themes were: providing support, way forward, positive role models, and positive impacts. The second part examines the program through the lens of the participants. The emergent themes were: strengths of CEPS, facilitators supported learning, personal changes attributed to CEPS, and perspective transformation.

\section{Facilitators' Perspectives}

Both facilitators, Aisha and Darcy, had been participants in the program in years prior to the study and commented on the strengths of the program, as they saw it. Aisha believed that "the strengths in the program were the cultural and social components." She commented on sharing her own experiences to help support students, and observed the importance of the program in providing a fresh start for participants. Darcy noted his new role as a leader and a role model. Both facilitators emphasized the benefits they gained from CEPS first as participants and then as facilitators.

Providing support. Some of the participants were parents or expectant parents. The facilitators adjusted the program to support the learning of such participants. Aisha, a parent herself, could provide support to those participants from her personal experiences. She said, "I shared with them so they won't feel that they're alone." Aisha provided an example:

One of the students was pregnant ... and she would ask me questions, in the social component. With the other students they had relationship issues, and I talked to them about my past relationships. I just shared what I experienced just to help them. So they wouldn't feel they're the only ones going through this. One of the students had family issues going on, and she was a teenager, I was a teenager ... so I shared with her my experiences. And tried to let them know it's not the end of the world.

One of the challenges in the program was to continue to encourage the participants to keep going despite their personal issues. Aisha explained that some participants "want to give up. That's how they felt. And I told them it's just another day; it's just a bad day. And whenever there's a bad day, good comes out of it." Participants noted in their own interviews the value of such personal anecdotes in helping them to remain in the program.

Way forward. The CEPS program is an important way forward to participants who often have had serious challenges in the past. Aisha referenced a conversation with a former participant of the program. She reported that:

He's working, he's going to be getting married in August, he's staying out of trouble... and he was also asking for his certificate!" He wanted the certificate to "add to his resume. He's trying to go down a positive road....He came to the program to try to better his life.

Positive role models. Having a leadership role was new and significant for Darcy. He said, "I understood now I am a role model and I got to watch how I behave. Back when I took CEPS and that really helped me become a gentleman." Darcy pointed out how important positive role models were for participants, some of whom had "pretty rough lives." Many of the participants had personal issues that interfered from time to time and distracted them from the program. For example, one participant ended up "going back to jail because he broke his parole conditions." Darcy remembered "encouraging him to the end." Despite this setback, when interviewed by researchers the young man to whom Darcy was referring indicated "his life is different even though it doesn't look like it." This comment indicates that although progress may not be clearly apparent to an observer, internally this young man feels he is moving forward.

Positive impacts for facilitators. Both facilitators noted that one of the empowering things about their facilitator role was the respect they had from students: "the students really looked up to us." Both facilitators also noted personal growth and realization of their own strengths. Aisha acknowledged, "because of CEPS I realized that I'm 
more interested in psychology." She came to this realization because she saw her natural ability for "talking with the students and helping them. That was my strength. I was able to relate to them, and give them comfort; I'd help them a lot. So I'd seen where my strength was from facilitating CEPS." As a result of CEPS, Aisha also became more connected to the tradition of procuring traditional medicines that grow in Cree lands.

Darcy also reflected on how he had changed as a result of the program. "I took CEPS back in 2010 and I learned a lot . . . I learned more about myself and how to express myself . . . the program teaches you a lot of things you don't usually learn." Darcy reflected on how he felt lost before the program, and that this had changed as a result of his participation in the program: "I don't see this lost guy ... I see myself as a leader now." Darcy noted another result of being a participant in CEPS was self-care. "I just started to take care of myself better." Darcy made a number of changes to his lifestyle that he attributed to being a participant in the program. He started getting to bed early and looking for work. He also became more confident. Darcy said, "[CEPS] taught me to stand up for myself." Darcy graduated from high school prior to enrolling in CEPS and upon completion of CEPS, he felt like he had graduated again: "I actually felt like I graduated in life." As a result of being a participant in CEPS, he said, "I have options now. I can see possibilities I can take. It was empowering, it just empowered me."

The CEPS program led Darcy and Aisha to understand themselves better as participants and then later as facilitators. This program helped them to make important personal changes in the way they saw the world and their role in it. Both facilitators enjoyed teaching in the program and wanted to make it even better. They saw positive change in the participants and in themselves.

\section{Participants' Perspectives}

Participants shared their perceptions of the areas of strength of the CEPS program, the ways in which facilitators supported learning, personal changes attributed to CEPS, and perspective transformation.

Strengths of CEPS. Rebecca was very curious about the program at the beginning. She said, "I am just one of those people that wants to get to know the people around the program and me." All of the participants identified a number of strengths in the program. For example, Kelvin said, "It's a good program to be sure." He enjoyed "participating in events and socializing and liked what we were doing and stuff."
Cultural component. The cultural component was viewed as an important element contributing to the strength of CEPS. For Helen, hearing from knowledgeable speakers on Aboriginal culture was a valuable part of the program:

They had a lot to share, and they also brought stuff from our culture, and they explained what they were for. So the Peace Pipe, they explained what that's used for, and what kind of ceremonies that's used for, and what other Peace Pipes they had. What the sage is for, and they would have their own medicine wheel, they would tell us all the different stuff that could have been used for in our life.

Georgina recalled that she "didn't know anything about [Aboriginal culture] and it made me feel like I really wanted to get to know what was going on and everything about it." Tanis liked the activities they did "including having the teachings taught to us by the Elders that came in . . They taught us how to smudge, and we made our own skirts, too." Erica liked "how they filled you up with information." She liked the readings and presentations the most, particularly those that involved Elders coming in to speak. There were also several class trips to different cultural land-based areas. Erica appreciated learning about the historical and cultural context of these traditional locations. She also enjoyed learning about the traditional medicines and traditional cultural activities like the Sun Dance and Sweat Lodge ceremonies.

Support. Rebecca discussed the strength of mutual support within CEPS. "We had a strong group that attended every day and we looked out for each other. Sometimes when someone wouldn't come we would call them." This supportive environment was helpful for participants. Erik commented on the social aspect of the program: "they had a lot of good ways of everyone just getting to know each other better and knowing each other as a person."

Facilitators. Erik really appreciated the quality of the facilitators for CEPS. He said, "They were part of us, part of the group but they were leading it. And they are our age too; and they were fun. That made everything easier." Rebecca also found beneficial the fact that there was one male and one female facilitator.

Life skills. Helen benefited from the life skills part of the CEPS program: in particular money and time management. She reflected: 
It helped me better manage my money and learn where I could make it more useful to survive. And the timemanagement part helped me when I make

appointments, to make them where I could be available, and actually go to the appointment.

Facilitator supported learning. One of the resounding comments about CEPS was how the facilitators supported the learning of the participants during the program. This is an important point, as it underscores the importance of having an authentic relationship with the facilitator for transformative learning experiences to occur.

The facilitators supported participant learning. For example, Kelvin noted, "Whenever we asked, [the facilitators would] come try to give us the full explanation in what we were learning." Kelvin also said: "You actually got to do learning activities, and then there were group discussions afterwards to share your thoughts and feelings about what was happening."

Rebecca recalled that the facilitators "were very helpful, and sometimes when I wasn't able to make it, they helped me out with a ride and stuff like that. They were very good ... They understood what you were going through." Tanis also said that the facilitators were open and engaged in helping participants grow. She said, "They explained things simply and they taught good [sic]. They made me understand a lot, and I learned a lot." Erica recalled that the facilitators used icebreakers every day to loosen everyone up and build a sense of collective identity within the group. She also liked that they used advanced organizers to help the participants to stay on track and to provide a way of letting them know what was coming each day. The facilitators encouraged the participants to "help each other." Erica observed, "I was proud of them. I just found it awesome to work with somebody our age who would understand and learn along with us."

Georgina really liked how the facilitators "took the time to explain everything to you." Georgina affirmed the quality of her experience in the program by responding, "I don't think there is anything that can be changed." She said, "It's a good experience and if there was another class that I would be able to take, I would want to go again."

The facilitators modeled a constructivist classroom through sharing circle activities. The participants did sharing exercises where, as Erik said, "everyone gets in a circle and you share one hobby or interest and someone else will raise their hand and say 'Oh I like doing that too.' " Erik disclosed that these experiences, which led to a strong group cohesion, were very significant for him and "that's what really made me want to do it and keep going."
One of the challenges that Erik identified was "not everyone [was] paying attention, not everyone [was] focusing on the stuff they [were] teaching. It gets distracting and affects everyone else's learning." However, Erik noted that the facilitators were very patient and would recap the lesson and while not everyone was always fully engaged, gradually the classroom environment improved.

Personal changes attributed to CEPS.

Participants noted several personal challenges they overcame during CEPS. These included shyness and lack of confidence to voice their thoughts during discussions or to volunteer to participate in various activities. For some participants sharing their experiences and reflections was difficult. For one participant a major challenge was homelessness. Rebecca discussed that she had "no place to stay then, and just having people around to support me in a way was very helpful."

Other participants shared that personal issues caused them to miss part of the program. For example, Helen missed class sometimes because "I would go drink the day before, and I would be hungover. Sometimes I wouldn't wake up or wake up late, and I would show up late, or I wouldn't go for the morning." However, Helen and other participants noted that as a function of CEPS, they became aware that their lifestyle was getting in the way of their personal growth.

Participants reflected on a number of changes they attributed to the material they learned in CEPS. For example, Kelvin felt connected to some of the participants and better connected with "family and friends." The CEPS program provided positive activities in the midst of many negative choices. Kelvin felt more confident and had moved on to the Youth Club where he was learning basic skills for his future success. Kelvin said, "CEPS got me on my feet, I guess. Got me going. Got me a job."

Rebecca really noticed how she had changed as a result of the program. She found the cultural component of CEPS most helpful. She said that the economic part of the program was also important:

The budgeting part was really helpful too because now I know how to save my money and the difference between want and need and stuff like that. That was really helpful because now I see like, Oh, do I need these pair of shoes? I'm like, my shoes are holey, I do need them. Or, do I just want a new pair of shoes?

Rebecca had started to save money. She had also learned to appreciate her family a little more. The CEPS program also inspired Rebecca to finish school and get a job. After CEPS ended, Rebecca enrolled in a youth program and now works in Thompson. 
Overall, she was grateful for the personal changes that CEPS brought about. The program even gave her the desire to get her driver's license. Rebecca now has both short-term and long-term goals.

Tanis also benefited from the program. She said, "Before I came to this program I wasn't even in school or anything. I wasn't working. [I was] doing nothing. But now I am in school after the program and I'm looking for a job." Tanis also related better to people. She wanted to get on with her life. Tanis said, "I am just thinking about it and I am not going to waste any more time." She had become more motivated.

Erica really enjoyed learning about her culture. As a result of this learning, she said, "I am wanting to get my Indian name, my Cree name". She had also developed a mentee relationship with an Elder. Erica liked learning about Aboriginal traditions and was acquiring the skills to do traditional arts after the program was over, and she was taking a great deal of pride in this pursuit. She was also inspired to go back to school and received a job offer after CEPS ended.

Georgina struggled with anxiety. This program gave her the strength "to really talk to people and get to know people." Because there were other people in the program with similar challenges, she felt comfortable talking about these challenges and felt confident that she, too, could overcome them. She felt CEPS changed her:

When you are in CEPS, it pushes you and it makes you want to go out there and do different things. It changes the way you see things and makes you want to push yourself to do things. CEPS makes you feel like you can do anything.

Georgina was inspired by CEPS and noted, "I'm more confident." In Georgina's words, CEPS gave her the "motivation to become a better person." Georgina also benefited from the cultural component in CEPS. She said, "[CEPS] makes me know more about how [my parents] grew up and my dad was in residential school and they told us a lot about residential school and how it was for those people." Georgina is planning to go back to school. She said, "I am going to go out there and go back to school now that I'm comfortable around people ... I can go back to school and get a higher education and become what I want to be." She wanted to get training so that she could work with children in a daycare.

Erik indicated that as a result of CEPS, "you just know how the world is now. I guess not the world, but where we live and where we are." He learned a lot in the program. He reminded the interviewer of his new found confidence by saying, "I'm pretty sure before the program I wouldn't have done an interview like this." CEPS gave Erik the confidence to speak out for himself and for the betterment of his community. CEPS gave Erik the strength to "just [feel] more socially active." Erik wanted to go home so that he could learn his language. Erik had developed a real need to understand who he was, and to know himself better through his language. He was also eager to work and felt more confident. As a result of CEPS, Erik felt that more work opportunities would be available to him, "Especially work wise. I will feel less limited to accept lower level jobs."

Helen said that after the program, "I got a job full-time, I always went to my shifts, and every time they asked me to cover someone's shift I would go. So I was financially stable." Helen said, "I'm more independent now. I treat people differently after taking the program. I treat them with respect now, as in before I wouldn't even look at them, I would ignore them." She learned a lot in the program and said of her compassion for others:

I'm more aware of other people, other people's feelings and my feelings now that I've taken the program. I know my role, especially at my job, I know my role as a daughter, and I know my role as a mother. I take it more seriously now. As in before, I was just up in the air, I didn't have stability, and I wouldn't have cared before.

Helen's reflection on what she learned in CEPS reminds us of the power of a program to create change. One of the most important benefits of the program was that the participants were learning to be less judgmental of themselves and others. Three quotations from the participants demonstrate the change in the participants' critical self-reflection of assumptions.

I used to be quiet and felt like when I was sitting there that people were going to judge me. "What are they going to think of me?' I used to worry about that and then taking CEPS, I realized that people are actually not judgmental, that they actually are really nice, and I feel a lot better and able to participate in the program.

Just appreciating [family and friends] more and knowing; I have more sympathy for them and understanding how I would feel if I were in their shoes. You just can't judge someone because they are going through a rough patch with drugs or something like that. You don't know what led them to that; the cultural and other parts [of CEPS] really helped.

I liked how I re-assessed myself, how I could make things better for myself in the future and the present. 
Perspective Transformation. The most important element from this analysis is the clear perspective transformation that participants described. The statements below made by each participant indicate substantive change in the their beliefs, values, and assumptions regarding themselves and their place in this world that speak to the transformative potential of the CEPS Youth Leadership Development Program.

Kelvin said that the program helped him realize, "[although] I did a lot of bad things [when I was younger], and I'm a good person. CEPS made me see myself as a person that's equal." Rebecca acknowledged that as a result of the program she had changed her way of thinking and treating herself and others. Tanis indicated that as a result of her participation in the program, "I'm focusing on myself and taking care of myself." These were two things she wasn't doing before the program. Thus, CEPS had made a significant difference in her life. Erica indicated that the program had altered the way she saw the world. She said that she had changed a lot as a result of her participation in the program.

Georgina said,

You see yourself different, like it makes you feel like a better person that you're not that old person you used to be. It makes you see yourself in a different way. You can do anything you want; you don't have to be afraid. It makes you speak out and just know, how to get to know people. I learned that I am able to talk to people, that people are able to listen to me, and I am able to help people that are able to talk to other people about different things.

Erik also felt that he had changed a lot as a result of participating in the program. He said,

I feel more like, just knowing about my ancestors and their culture and where they came from, because I was taught pretty different from what I've learned [in CEPS]. It's good to feel better about knowing the truth about the traditional ways. I am more outgoing in a group, and that is something about me that changed after the program. Another thing is I am better at talking and doing stuff like this.

Helen recognized,

After taking the program, it's like I care more. I care more about everything that I do, and if there's something I can't do, I do ask for help, but I try to reassess myself . . . how I could make it work.

\section{Discussion}

Based on the thematic analysis of interviews with the participants, there were several emergent themes, none more important, though, than recognizing the positive impact of providing relevant, meaningful, and purposeful instruction in a supportive learning environment. This was evident in how the participants identified with the learning that was taking place and how they thoroughly enjoyed their connections to the facilitators and classmates. Another emergent theme - provided that participants' essential financial needs were being met - was participants placed monetary incentives as secondary motivators compared to feelings of mastery, community, and purpose. It is also important to recognize the authentic relationships between the facilitators and participants as the provision of quality constructivist-based instruction. This connects well to the transformative potential of CEPS that places importance on dialogue, a holistic learning environment, the awareness of the learning context, and the importance of drawing from the life experiences of participants. These best practices were embedded into the program and the facilitators' instructional methods and led to participants feeling comfortable and trusting (Cranton \& Carusetta, 2004a, 2004b), which in turn facilitated opportunities for transformative learning to take place.

According to Taylor (2009), transformative learning can happen when participants become challenged to examine values and perspectives through which they make sense of the world and their thinking becomes substantially changed by the experience. Participants in the program shared how they were empowered and transformed as a result of the program, and how this program led them to understand their own social construction more deeply, as well as fostered more meaningful engagement with their community. Transformative learning theory provided an important means to see if participants were deeply impacted by what they were learning during CEPS and whether what they were learning could lead to substantive changes in how they understand and interact with the world (perspective transformation). CEPS proved to be an excellent program for formerly disengaged youth that led to a perspective change that was more enabling for the participants. Although this research did not include all participants in the program, we believe it fair to say that the CEPS Youth Leadership Development Program provided an extensive amount of knowledge that strengthened the physical, spiritual, emotional, and mental well-being of the participants. CEPS provided life skills that inspired and motivated youth to make positive choices to enhance the quality of their lives, and provided knowledge and leadership skill development. The CEPS program also developed the participants' agency to make a difference in their lives, their families, and their communities. CEPS offered a unique opportunity to build upon a young person's special gifts so that he or she can share them with the world. 


\section{References}

Assembly of Manitoba Chiefs. (n.d.). Retrieved March 21, 2012, from http://amc.manitobachiefs.com/index.php?option $=$ com_content $\&$ view $=$ article $\& i d=121 \&$ Itemid $=12$ 1

The Canadian Business Journal. (n.d.). Retrieved August 2, 2014 from http://www.cbj.ca/business_in_action/municipal/c ity_of_thompson_northern_manitoba.html

Cranton, P. (2006). Understanding and promoting transformative learning. San Francisco, CA: Jossey-Bass.

Cranton, P., \& Carusetta, E. (2004a). Developing authenticity as a transformative process. Journal of Transformative Education, 2(4), 276-293.

Cranton, P., \& Carusetta, E. (2004b). Perspectives on authenticity in teaching. Adult Education Quarterly, 55(5), 5-22.

Erikson, E. H. (1968). Identity, youth, and crisis (1st ed.). New York: Norton.

Kilgore, D., \& Bloom, L. R. (2002). "When I'm down, it takes me a while": Rethinking transformational education through narratives of women in crisis. Adult Basic Education, 12(3), 123.

Kumashiro, K. (2009). Against common sense: Teaching and learning toward social justice (2nd ed.). New York: Routledge Falmer.

Mälkki, K. (2010). Building on Mezirow's theory of transformative learning: Theorizing the challenges to reflection. Journal of Transformative Education, 8(1), 42-62. doi:10.1177/1541344611403315.

Merriam, S. B. (2009). Qualitative research: A guide to design and implementation. San Francisco, CA: Jossey-Bass.
Mezirow, J. (1991). Transformative dimensions of adult learning. San Francisco, CA: Jossey-Bass.

Mezirow, J. (2000). Learning as transformation: Critical perspectives on a theory in progress. San Francisco, CA: Jossey-Bass.

Mezirow, J. (2012). Learning to think like an adult: Core concepts of transformation theory. In E. W. Taylor, \& P. Cranton (Eds.), The handbook of transformative learning theory, theory, research, and practice (pp. 73-96). San Francisco, CA: Jossey-Bass.

Phinney, J. S., \& Chavira, V. (1992). Ethnic identity and self-esteem: An exploratory longitudinal study. Journal of Adolescence, 15, 271-281.

Taylor, E. W. (2009). Fostering transformative learning. In J. Mezirow, \& E. W. Taylor (Eds.), Transforming learning in practice: Insights from community, workplace, and higher education (pp. 3-17). San Francisco, CA: Jossey- Bass.

Tisdell, E. J. (1998). Poststructural feminist pedagogies: The possibilities and limitations of feminist emancipatory adult learning theory and practice. Adult Education Quarterly, 48(3), 139156.

Tisdell, E. J. (2007). Popular culture and critical media literacy in adult education: Theory and practice. New Directions for Adult \& Continuing Education, (115), 5-13. doi:10.1002/ace.262.

Welch, P. (2006). Feminist pedagogy revisited. Learning \& Teaching in the Social Sciences, 3(3), 171-199.

Yorks, L., \& Kasl, E. (2006). I know more than I can say: A taxonomy for using expressive ways of knowing to foster transformative learning. Journal of Transformative Education, 4(1), 43-64. doi:10.1177/1541344605283151

\footnotetext{
About the Authors:

Chris Brown is an associate professor in the Educational Psychology and Student Services department at Brandon University, Manitoba. Canada.

Brandee Albert is currently a social worker in the School District of Mystery Lake, Thompson, Manitoba, Canada. She is also the VOICE coordinator for the Thompson Community Circle through Brandon University.
} 